\title{
1 Design and optimization of electrochemical cell potential for 2 hydrogen gas production
}

4 Nawar K. Al-Shara ${ }^{a}$, Farooq Sher ${ }^{\mathrm{b},}$, Sania Z. Iqbal ${ }^{\mathrm{c}}$, Oliver Curnick ${ }^{\mathrm{d}}$, George Z. Chen ${ }^{\mathrm{a}}$

5 a Department of Chemical and Environmental Engineering, University of Nottingham, University

6 Park, Nottingham NG7 2RD, UK

7 b School of Mechanical, Aerospace and Automotive Engineering, Faculty of Engineering,

8 Environmental and Computing, Coventry University, Coventry CVI 2JH, UK

$9{ }^{c}$ Department of Biochemistry, University of Agriculture, Faisalabad 38000, Pakistan

$10{ }^{\mathrm{d}}$ Institute for Future Transport and Cities, Coventry University, Coventry CV1 5FB, UK

$12 *$ Corresponding author.

13

14 E-mail address: Farooq.Sher@ coventry.ac.uk (F. Sher)

15 Tel.: +44 (0) 2477657754

16

\section{Abstract}

18 This study deals with the optimization of best working conditions in molten melt for the

19 production of $\mathrm{H}_{2}$ gas. Limited research has been found that how electrochemical process occurs

20 through the steam splitting via molten hydroxide. 54 combinations of cathode, anode, temperature

21 and voltage have been tested for the optimization of best working conditions with molten

22 hydroxide for hydrogen gas production. All this electrochemical investigation was carried out at

23225 to $300{ }^{\circ} \mathrm{C}$ temperature and 1.5 to $2.5 \mathrm{~V}$ applied voltage values. The current efficiency of $90.5 \%$,

$2480.0 \%$ and $68.6 \%$ had been achieved using stainless steel anodic cell with nickel, stainless steel

25 and platinum working cathode respectively. For the nickel cathode, the increase in the current

26 directly affected the hydrogen gas flow rate at the cathode. It can be hypothesized from the noted

27 results that increase in current is directly proportional to operating temperature and applied

28 voltage. Higher values were noted when the applied voltages increased from 1.5 to $2.5 \mathrm{~V}$ at 300 
$29{ }^{\circ} \mathrm{C}$, the flow rate of hydrogen gas increased from 1.5 to $11.3 \mathrm{~cm}^{3} \mathrm{~min}^{-1}, 1.0$ to $13 \mathrm{~cm}^{3} \mathrm{~min}^{-1}$ in case

30 of electrolysis @ stainless steel and @ graphite anode respectively. It is observed that the current

31 efficiency of stainless steel anodic cell was higher than the graphite anodic cell. So, steam splitting

32 with the help of molten salts was shown an encouraging alternate to current methodology for $\mathrm{H}_{2}$

33 fuel production.

35 Keywords: Sustainable energy; Splitting steam; Electrolysis; Hydrogen gas production; 36 Electrochemical cell and Variable cathodes.

\section{Introduction}

Hydrogen $\left(\mathrm{H}_{2}\right)$ has received focus among several alternative fuel sources because it provides

40 the principal advantages and fulfils ideal fuel requirements. Hydrogen fuel is the same as

41 electrochemical energy in terms of being a high-efficiency energy carrier and when it is used, it

42 can lead to zero or near-zero emissions. For this reason, recently, many researchers and

43 organizations have propagated $\mathrm{H}_{2}$ fuel to minimise global warming hazards. The most studied

44 technique for the production of $\mathrm{H}_{2}$ gas from water is through the electrolysis of aqueous alkaline

45 hydroxide solutions [1].

46 The published studies [2,3] clearly mention that 19 methods exist in for hydrogen gas

47 production, including plasma arc decomposition, dark fermentation, coal gasification,

48 biophotolysis, artificial photosynthesis, electrolysis and others. It was also concluded that among

49 all electrical hydrogen production via electrolysis gives good energy efficiency as well as with the

50 lowest cost rate. Electrolysis is the most common methodology to yield $\mathrm{H}_{2}$ gas using water as a

51 clean and renewable energy resource. Electrolysis has high product purity up to 99.9 vol\%, this 
52 purity can be attained on both scales large and small. The only setback is that electrolysis can also

53 be responsible for the emission of $\mathrm{CO}_{2}$ gas if a non-renewable energy resource has been used to

54 produce the required electrochemical energy $[4,5]$. The materials used to construct the electrolysis

55 cell must also withstand certain tough operating conditions and need further development in order

56 to commercialize this clean energy method for producing hydrogen gas as fuel. This clean fuel can

57 be yielded directly from splitting water using different techniques. These techniques include photo

58 electrochemical hydrogen production (photo electrolysis), thermochemical water splitting and

59 water electrolysis [6]. This study focuses on using electrolysis to split water into its core

60 constituents of $\mathrm{H}_{2}$ and $\mathrm{O}_{2}$ gas respectively [7].

61 Three main methods are currently under consideration for the production of hydrogen via

62 water electrolysis: proton exchange membrane [8], solid oxide cell and alkaline melt. The

63 electrochemical cell of alkaline electrolysis comprises of an alkaline aqueous electrolyte, two

64 electrodes and a microporous separator for ion conduction. The hydroxyl ions generated at the

65 cathode electrode are migrated to the anode and the remaining $\mathrm{H}^{+}$ions at the cathode electrode

66 combine with electrons to form $\mathrm{H}_{2}$ gas [9]. The two electrodes are cathode and anode, from which

67 the cathode metal possesses a good catalytic activity and the anode electrode possesses an oxide

68 coating layer. The molten melts of $\mathrm{NaOH}$ and $\mathrm{KOH}$ are applied as electrolyte solutions. The ion-

69 conducting microporous separator permits the movement of hydroxyl ion and restricts the

70 involvement of produced oxygen and hydrogen. The efficiency of alkaline electrolysis can reach

$7170 \%[10]$.

72 Electrochemical studies focused on molten hydroxides for the generation of hydrogen fuel

73 via water splitting were demonstrated by Licht et al. and Al-Shara et al. [11,12]. These studies

74 investigated various mixed and pure alkali hydroxides as electrolytes such as $\mathrm{Ba}(\mathrm{OH})_{2}, \mathrm{KOH}$, 
$75 \mathrm{LiOH}, \mathrm{NaOH}$ at temperatures between 200 and $700{ }^{\circ} \mathrm{C}$. The applied voltage range was maintained 76 between 1.1 and $2.3 \mathrm{~V}$ using a nickel and platinum metal as an anode and a nickel plate as a 77 cathode, respectively. It is also mentioned that molten hydroxides act as catalyst therefore there is 78 no need for any additional heat [12]. A detailed study was performed by Nagai et al. [13], in which

79 they focused on the $\mathrm{H}_{2}$ production potentials and efficiency of the electrochemical cell with Ni-

$80 \mathrm{Cr}-\mathrm{Fe}$ alloy as the cathode material, under atmospheric pressure and using $10 \mathrm{wt} \%$ of $\mathrm{KOH}$ 81 aqueous solution.

82 Licht et al. [14] reported an electrochemical study for the generation of ammonia from steam 83 and air via an equimolar ratio of molten $\mathrm{NaOH}-\mathrm{KOH}$ with suspended nano- $\mathrm{Fe}_{2} \mathrm{O}_{3}$ particles using 84 nickel electrodes at a temperature of $200{ }^{\circ} \mathrm{C}$ and an applied voltage of $2 \mathrm{~V}$. Ganley [15] studied 85 the direct electrolysis by using the experimental conditions of $18 \mathrm{M}$ of $\mathrm{KOH}, 400{ }^{\circ} \mathrm{C}$ temperature, 86 8.7 MPa partial pressure, fixed cathode of monel alloy and variable anodes of (cobalt-plated nickel, 87 lithiated nickel, monel alloy, nickel). At temperatures as low as $80^{\circ} \mathrm{C}$, the study of Anani et al. 88 [16] discovered a technique to produce high purity hydrogen gas at the cathode while maintaining 89 high current efficiency during the electrolysis of hydrogen sulphide. The intermediary solution 90 resulting in the generation of the latter contained an equimolar concentration of $\mathrm{NaOH}$ and $\mathrm{NaHS}$

91 at the experimental temperature. The two-electrode electrolysis process has been used in this study

92 to apply a voltage to the cathode and anode to split steam through eutectic molten hydroxide.

93 Subsequently, $\mathrm{O}_{2}$ and $\mathrm{H}_{2}$ gas were collected from the anode and cathode compartment respectively.

94 Hydrogen gas was detected by using a hydrogen gas tube and hydrogen gas sensor where the actual 95 rate of $\mathrm{H}_{2}$ gas yield was measured using the pneumatic trough method.

96 There were limited studies that have been carried out how the electrochemical process occurs 97 through the steam splitting with the help of molten salt's solution for $\mathrm{H}_{2}$ gas production. This study 
aims to record an escalation in the efficiency of $\mathrm{H}_{2}$ gas production by optimizing several operating

99 parameters such as temperature and applied voltage; or by changing the material used for cathode

100 or anode construction in the electrochemical cell. The electrochemical analyses were performed

101 by using graphite and stainless anodes and platinum, stainless steel and nickel cathodes. From

102 literature it is analyzed that $\mathrm{Ni}$, Pt and St.st metals were suitable for electrolysis because they are

103 stable under highly alkaline solution, low cost, easily available $[17,18]$. 54 combinations of a

104 cathode, anode along with different operating variables have been tested for the production of $\mathrm{H}_{2}$

105 gas through the splitting of steam via molten hydroxide salt. This was a comparative study also,

106 based on finding the most efficient electrochemical cell that increased the efficiency of steam

107 splitting through electrolysis of eutectic molten hydroxide. All this electrochemical investigation

108 was carried out at 225 to $300{ }^{\circ} \mathrm{C}$ temperature and 1.5 to $2.5 \mathrm{~V}$ applied voltage values.

\section{2. Experimental}

$110 \quad$ 2.1. Two-electrode electrolysis

111 A mixture of $300 \mathrm{~g}$ of $\mathrm{NaOH}-\mathrm{KOH}(49-51 \mathrm{~mol} \%)$ was used as the electrolyte and placed

112 inside the retort, before being heated to a temperature of $300{ }^{\circ} \mathrm{C}$ for $24 \mathrm{~h}$. It must be noted here

113 that the retort has already been placed inside the pore of the vertical tube furnace. A pure alumina

114 crucible was used to hold the mixture of hydroxide salt. Stainless steel, platinum and nickel were 115 used as the cathode; whereas stainless steel and graphite were used as the anode during the 116 experiments, respectively. Prior to immersing the cathode and anode inside the eutectic molten

117 hydroxide to begin electrolysis, each electrode was placed inside an alumina tube with $20 \mathrm{~mm}$ 118 inside diameter.

119 The reason for covering the electrodes with an alumina tube was to prevent the mixing of $\mathrm{H}_{2}$ 120 gas with the $\mathrm{O}_{2}$ gas formed as a result of the electrolysis process. This compartment should be 
121 tightly sealed to avoid any gas leakage. The diameter of the different electrodes used in this study

122 and the calculated areas are listed in Table 1 . The total duration of the steam electrolysis process

123 was approximately $1800 \mathrm{~s}$ after which hydrogen gas was collected. Direct current (DC) source of

124 power was used for voltage applications on both electrodes.

125 This applied voltage was altered between $1.5 \mathrm{~V}$ and $2.5 \mathrm{~V}$. It is worth mentioning that

126 although the voltage is listed as being positive, the negative terminal of the DC source was actually

127 connected to the cathode. Therefore the polarity of this electrode, in reality, is negative.

\subsection{Steam generation}

Before the electrolysis process was performed, a combination of argon gas and steam was

130 introduced to the eutectic molten hydroxide. Argon gas worked as a carrier for steam introduction

131 into the bottle. In this study, steam was generated by placing a $500 \mathrm{~mL}$ dreschel bottle filled with

$132300 \mathrm{~mL}$ of distilling water, on a hot plate heater. The temperature of the hotplate can be varied

133 from the insert temperature button. The argon gas inlet stream was connected to the inlet of the

134 dreschel bottle head which was directly dipped into hot, distilled water. Then, the argon gas left

135 the dreschel bottle from the outlet head. The stream of argon gas loaded with steam was connected

136 to a ceramic tube which was then submerged in molten hydroxide [19].

137 Distilled water was heated up to $70{ }^{\circ} \mathrm{C}$. The argon gas stream bubbled through the hot water 138 and left the bottle loaded with water vapor. This was then introduced directly to the molten

139 hydroxide. The humidity of the argon gas when it left the dreschel bottle at a temperature of $70{ }^{\circ} \mathrm{C}$ 140 and an argon flow rate of $40 \mathrm{~cm}^{3} \mathrm{~min}^{-1}$, was about $50 \%$. The steam flow rate was about $7.28 \mathrm{~cm}^{3}$ $141 \min ^{-1}$ and was calculated using Dalton's law for gases. The residence time required to achieve 142 saturation between the eutectic molten hydroxide and the humid mixture of argon gas was 
143 influenced by the salt volume in the crucible. The residence time needed to achieve the saturation

144 between eutectic molten hydroxide and a humid argon gas flow rate was between 2-6 min.

\subsection{Hydrogen gas production analysis}

The start of the generation of $\mathrm{H}_{2}$ gas at the cathode was detected by using a Gastec gas

147 detector tube. This gas tube detector is capable of measuring up to 2 vol\% of hydrogen gas. Thin

148 glass tubes are usually available with outer calibration scales. These calibration marks help them

149 to measure the concentrations directly [20]. Tubes undergo stringent quality control with each

150 production percentage independently tested and calibrated.

151 A hydrogen gas sensor pro-gasbadge was also used to detect hydrogen gas produced up to

$1522000 \mathrm{ppm}$. This sensor has an interchangeable "smart" sensors monitor for hydrogen gas. There is

153 a direct communication between the sensor and the Docking Station with the help of an infrared

154 interface. As the gas produced at the cathode was confirmed as hydrogen gas, the production rate

155 was measured using the water displacing method (Pneumatic Trough) and calculated as an actual

156 gas rate using Dalton's law for gases. The hydrogen gas production rate due to steam splitting via

157 the electrolysis of eutectic molten hydroxide was calculated using Eq. (1):

$$
\text { Production rate }=\frac{\text { Mass of } \mathrm{H}_{2} \text { produced }}{\left(\text { Immersed area of cathode } \times \text { Duration of } \mathrm{H}_{2} \text { production }\right)} \times 100 \%
$$

161 The values that were inserted into this equation were determined as follows. The mass of $\mathrm{H}_{2}$ gas

162 production was found from the multiplication of the molecular weight and actual number of moles

163 of the $\mathrm{H}_{2}$ gas. The actual number of moles can be measured using the equation of state of gases at 164 a temperature of $25^{\circ} \mathrm{C}$, partial pressure of hydrogen gas and the actual volume of hydrogen. The 
165 partial pressure of hydrogen was calculated using Dalton's law for gases at $25{ }^{\circ} \mathrm{C}$ and 1 atm. The 166 actual volume of hydrogen gas was calculated by multiplying the mole fraction of hydrogen gas 167 by the total volume of the collected gas during the electrolysis process from the cathode 168 compartment using water displacement method. As for the current efficiency of hydrogen gas 169 production, this was calculated using Eq. (2):

$$
\text { Current efficiency }=\frac{\text { Charge needed to produce } \mathrm{H}_{2} \text { in theory }}{\text { Charge passed during electrolysis }} \times 100 \%
$$

The values that were inserted into this equation were determined as follows. The amount of 174 electric charge $(Q)$ passing through the electrolytic mixture during hydrogen gas production can 175 be obtained by integrating the current time plots. To calculate the charge needed to produce

176 hydrogen gas, in theory, the number of electrons involved to split steam to hydrogen gas

177 was multiplied by the Faraday constant $(96485 \mathrm{C} / \mathrm{mol})$ and the number of moles of hydrogen gas 178 produced. Thus, higher electric charge flow will indicate more hydrogen gas produced at the 179 cathode.

\section{Results and discussion}

The minimum amount of voltage and the overall amount of electrical energy needed for the

182 generation of $\mathrm{H}_{2}$ gas from water splitting at $25^{\circ} \mathrm{C}$ temperature is $1.23 \mathrm{~V}$ [21]. The net reaction of 183 water splitting can be represented as in Eq. (3):

$$
\mathrm{H}_{2} \mathrm{O}+2 \mathrm{e}^{-} \leftrightarrow \mathrm{H}_{2}+1 / 2 \mathrm{O}_{2}
$$

185 In practice, as because of the bubble formation, low reaction rate and the activation energy barrier 186 of the reaction, the electrochemical cell voltage needs to be larger than the required cell voltage 187 Therefore in this study, the cell voltages used were kept above the minimum cell voltage of 1.23 
$188 \mathrm{~V}$ even though it needs to be lower than this minimum value at high operating temperatures. The

189 higher applied voltages between 1.5 and $2.5 \mathrm{~V}$ to split water were arranged in such an order to

190 overcome any barrier for the electrolysis process and ensure continuous hydrogen gas production.

191 The electrolysis process was operated in a temperature range between 225 and $300{ }^{\circ} \mathrm{C}$.

\subsection{Performance of stainless steel anodic cell}

Stainless steel was employed as the anode material in the electrolysis process. Therefore it

194 should be mentioned that when it was employed at high temperatures in the eutectic molten

195 hydroxide, it had a passivate type behavior even though it was used in a corrosive environment

196 [22]. The stainless steel anode undergoes passivation with the creation of an outer layer shield, and

197 there is no influence on the response of the current-time plot which is directly reflected in the rate

198 of hydrogen gas formation. These results were repeatedly obtained for four times over, and thus

199 noises were not caused by experimental errors. The noise, as mentioned earlier, was due to steam

200 splitting and the development of bubbles on the surface near the nickel cathode.

$201 \mathrm{Ni}, \mathrm{Pt}$ and St.st electrodes were used individually as cathode in the designed electrochemical

202 cell, to study the electrolysis and resultantly hydrogen production [23], against St.st anode. The

203 other applied conditions were changing continuously to find the optimum ones, including

204 temperature and voltage. Fig. 1 shows the current-time responses at operating temperature $300{ }^{\circ} \mathrm{C}$.

205 At this operating temperature, a different voltage was applied (1.5, 2.0 and $2.5 \mathrm{~V}$ respectively).

206 These electrolysis processes were carried out as mentioned previously, under a steady argon gas

207 flow rate $40 \mathrm{~cm}^{3} \mathrm{~min}^{-1}$ and a fixed steam flow $7.23 \mathrm{~cm}^{3} \mathrm{~min}^{-1}$. The reason for this comparison is

208 to find out the most efficient cathode material during the electrochemical process for a higher rate 209 of hydrogen gas production. 
In addition to nickel, platinum metal was also selected as a cathode for the hydrogen

211 evolution in the eutectic molten hydroxide [24]. The recorded current-time plots for all the tested

212 combinations are shown in comparison against the St.st anode in Fig. 1 at different applied

213 voltages. As mentioned previously, platinum is a precious metal and this prevents it from large

214 scale industrial use, limiting its usage for laboratory scale investigations. In this study, a platinum

215 wire of $0.5 \mathrm{~mm}$ diameter was used. Since the diameter of the used platinum is very small, it was

216 necessary to increase the surface area that was exposed to the electrolyte to be approximately the

217 same as the nickel electrode surface area. This was done to ensure a smooth comparison of current

218 flow and production rate of hydrogen gas at the same operating conditions. Therefore, in order to

219 achieve a surface area of $2.55 \mathrm{~cm}^{2}$, it was simply rolled into a spiral shape with $15 \mathrm{~cm}$ of the wire

220 length. This increase in the surface area significantly contributed to increasing the current flow

221 value at different applied voltages.

222 It can be observed from the current-time plots @ St.st anode that current flow increases with 223 an increase in the applied voltage at the applied operating temperatures. After electrolysis, no 224 change can be observed on Pt electrode's surface. The reason for there being no change in the 225 surface area of the electrode is because platinum is an inert metal and does not inhibit the reaction 226 occurring at its surface. It simply acts as a means to transfer electric charge from the power supply 227 to the electrolyte without undergoing any change. Platinum can also be classified as a corrosion 228 resistance metal to specifically withstand sodium hydroxide melt under suitable conditions [25].

229 Stainless steel metal was also used as a cathode in the eutectic molten hydroxide to compare 230 with other tested materials at the same operating conditions. It can be observed from Fig. 1 that 231 the current increases with an increase in the applied voltage. It is observed that at $225^{\circ} \mathrm{C}$, the 232 current response is stable and the current increases approximately with an increment of $0.2 \mathrm{~A}$ for 
233 every $0.5 \mathrm{~V}$ increase in the applied voltage. This observed phenomena of the current at $225{ }^{\circ} \mathrm{C}$ is

234 not applicable when the temperature is increased to $300{ }^{\circ} \mathrm{C}$. However, when the temperature

235 increases, the current response curve begins to appear noisy, particularly at higher applied

236 voltages. The escalation in the production of molecules of $\mathrm{H}_{2}$ gas around the cathode is mainly

237 liable for this noisy response of the current-time plot. Further surface morphology can be

238 considered for this in future for more comprehensive analysis.

239 The important point that can be observed from the results of current time plot is that the

240 overall recorded current is the highest when using the nickel as cathode material during electrolysis

241 inside the eutectic molten hydroxide might because of its good catalytic potentials [26]. These

242 observed results are consistent for the nickel electrode at different applied voltages and different

243 operating temperatures. Furthermore, for the nickel electrode, when the applied voltage increases

244 from 1.5 to $2.5 \mathrm{~V}$, the current increased accordingly as confirmed from the mentioned plots and

245 are in accordance with the literature [27].

246 In the testing, it was observed that at $225^{\circ} \mathrm{C}$ the current increases from $0.2 \mathrm{~A}$ at an applied

247 voltage of 1.5 to $1.4 \mathrm{~A}$ at an applied voltage of $2.5 \mathrm{~V}$. For stainless steel and platinum electrodes,

248 the recorded current-time plots show that their current responses are approximately the same at

249 different applied voltages and different operating temperatures. While at $300{ }^{\circ} \mathrm{C}$ temperature, the

250 current is recorded comparable, little bit higher for St.st than Ni at 1.5 and $2 \mathrm{~V}$. It should be noted

251 here that the steam and argon mixture was bubbled inside the eutectic molten hydroxide for an

252 approximate duration of 600-900 s before the electrolysis process was started. From these plots

253 obtained during electrolysis, the current flow observed was with some level of noise in most

254 conditions. This noise observed is quite typical during electrolysis of steam via eutectic molten

255 hydroxide and during the formation of hydrogen gas bubbles around the cathode. 
When hydrogen molecules are formed, they migrate away from the cathode in order to allow

257 other steam molecules to be split into forming new hydrogen molecules along with the oxygen.

258 This transfer of the hydrogen and steam molecules to and from the nickel cathode surface during

259 the electrolysis process can be listed as the reason for the noise noticed in the current-time plot. It

260 is significant to mention here that the nickel cathode is highly stable for molten hydroxide water

261 splitting as stated by literature [11], that corroborates with these research findings.

262

263

264

265

266

267

268

269

270

271

272

273

274

275

276

277

278

\subsection{1. $H_{2}$ gas production potentials @ anodic stainless steel cell}

The production of $\mathrm{H}_{2}$ gas was analysed using three methods, including Gastec gas detector tube, hydrogen gas sensor (PRO-GASBADGE) and water displacement method. The gas sensor monitored the hydrogen gas produced up to 2000 PPM. The hydrogen gas sensor detected the hydrogen gas between 655 to 705 PPM at an applied voltage of $1.5 \mathrm{~V}$ to the electrolysis cell and at more than 2000 PPM at an applied voltage of $2 \mathrm{~V}$. This confirmed that the only gas produced at the cathode is hydrogen. To quantify the amount of hydrogen gas produced at the cathode, the gas flow was collected in a measuring cylinder using the water displacement method. The hydrogen gas was collected and measured over a period of 10 minutes intervals.

The process was repeated four times and the production rate remained approximately constant. Fig. 2 shows the rate of hydrogen gas production at different cathodes (Ni, Pt, and St.st) at different operating temperatures and different applied voltages respectively. It is clear from this data that a steady increase in the hydrogen gas production rate at the cathode can be noticed when an increase in the operating temperature and applied voltage respectively, is enforced. This trend is valid for all examined cathode materials. Furthermore, the flow rate of hydrogen gas using a nickel electrode recorded the highest value in comparison to the other two used cathode materials i.e. stainless steel and platinum in this order respectively. For example, the hydrogen gas flow rate 
279 at $250{ }^{\circ} \mathrm{C}$ and applied voltage of $2 \mathrm{~V}$ using a nickel, stainless steel and platinum cathode were 5.0,

$2803.5,3.0 \mathrm{~cm}^{3} \mathrm{~min}^{-1}$ respectively. These results indicate that nickel has an enhanced level of catalytic

281 activity in the current eutectic molten hydroxide, contributing towards splitting the steam with

282 higher efficiency. Hydrogen gas production rates calculated with Eq. (1).

283

284

285

286

287

288

289

290

291

292

293

294 side reactions happened. When stainless steel was used as cathode against the same anode

295 efficiency reached up to $90 \%$. When interpreting the hydrogen gas production rate and current

296 efficiencies, different factors that need to be taken into account are the ionic transfer and gas bubble

297 behavior in the electrolyte. These factors, in turn, influence the current during electrolysis. The

298 transfer of ions is measured from the flow field and viscosity of the electrolyte solution. With the

299 development of the electrolysis process, viscosity increases as a result of electrolyte concentration.

300 That's why constant steam addition is carried out to preserve the constant viscosity and 301 concentration of the electrolyte [28,29]. Yet, greater transport does not mean greater $\mathrm{H}_{2}$ generation 
302 but it is right to say that it is associated with fast reaction rates. The more the reaction rate, the

303 more will be the bubbles formed, and this can adversely obstruct interaction of electrolyte solution

304 with electrode material [29]. For future work, to speed up the exit of the bubbles and eliminate

305 them from the respective electrode compartment, the recirculation approach can be mechanically

306 applied to electrolytes.

\section{7}

308

309

310

311

312

313

314

315

316

317 similar at operating temperatures of $225{ }^{\circ} \mathrm{C}$ and $250{ }^{\circ} \mathrm{C}$, the applied voltages of 1.5 and 2.0 318 respectively.

\subsection{Performance of graphite anodic cell}

Further electrochemical investigation undertaken in the eutectic molten hydroxide uses graphite as the material for the anode and alternates between nickel, platinum and stainless steel as the cathode. The reason for using graphite in place of stainless steel in this study is to compare the effect of changing the anode material on the electrolysis cell performance. Specifically, it must be investigated whether it has a direct effect on the hydrogen gas production rate and the current efficiency. This cell performance was also tested at different operating temperatures and different applied voltages. The current-time plot shown in Fig. 4 is noted at $300{ }^{\circ} \mathrm{C}$ respectively. These electrolysis processes were performed for $1800 \mathrm{~s}$ under an argon gas atmosphere. It is observed that the plots of current response using nickel and stainless steel electrodes is approximately

Alternately, when the operating temperature of the eutectic molten hydroxide is raised to $300{ }^{\circ} \mathrm{C}$, the current response using a nickel cathode becomes higher than for the stainless steel cathode. This difference between the former and latter is approximately $0.2 \mathrm{~A}$ and $0.4 \mathrm{~A}$ at $2.0 \mathrm{~V}$ and $2.5 \mathrm{~V}$ respectively as shown in Fig. 4. On the other hand, the current response using a platinum cathode is recorded as the lowest among the three different materials at different operating temperatures and applied voltages respectively. 
The electro-activity of the nickel cathode increased during electrolysis with increasing temperature. Platinum, however, showed no change in its electro activity even when the operating

327 temperature of the eutectic molten hydroxide or the applied voltages was increased respectively.

328 This finding can be considered as a promising finding for potentially novel, green technology

329 aiming at producing hydrogen gas using cheap, untreated metal instead of precious platinum metal.

330 The collection of the gas using water displacement method was carried out for 10 min and repeated 331 twice to confirm the accuracy of the gas production rate.

\section{2}

\subsection{1. $H_{2}$ gas production potentials @ anodic graphite cell}

The hydrogen gas flow rate increases with an increase in the operating temperatures of the eutectic molten hydroxide and when the applied voltage increases during electrolysis, as seen in Fig. 5. For the nickel cathode, the hydrogen gas flow rate produced during electrolysis at $300{ }^{\circ} \mathrm{C}$ and an applied voltage of $2.5 \mathrm{~V}$, records the highest flow rate followed by stainless steel and platinum under the same operating conditions. Alternately, the nickel electrode electro-activity for producing hydrogen gas reduces at a low temperature of $225^{\circ} \mathrm{C}$ and at an applied voltage of 1.5 $\mathrm{V}$ to be lower than the stainless steel electrode gas flow rate at the same operating conditions, as seen in Fig. 5 [30]. When comparing the hydrogen gas flow rate for both the anodes made of stainless steel and graphite respectively; and using different cathode metals, no significant change can be observed in the gas flow rate as seen in Figs. 2 and 5.

It is still imperative in this regards to mention that when graphite is used as an anode, the reduction process can possibly be obstructed by carbon particles blocking the pores of the oxide. This can prevent electrolyte contact with the oxide and significantly hamper the overall electrolytic process as mentioned by [31]. Therefore, it is important to take care when using graphite repeatedly to avoid contaminating the electrolyte and contributing to unfavorable side reactions. The 
348 production rate for each electrode was calculated using equation (1). The production rate for

349 hydrogen gas increases with an increase in the operating temperature of the eutectic molten

350 hydroxide. The platinum cathode did not exhibit this behavior because its production rate 351 decreases with increasing temperature. This behavior was seen even when stainless steel was used

352 as an anode. The production rate of hydrogen gas decreases when the temperature increases to 300

$353{ }^{\circ} \mathrm{C}$. This result leads to the conclusion that electro-activity of platinum metal inside the eutectic 354 molten hydroxide decreases with increasing operating temperature.

\subsubsection{Current efficiency of the cell}

Fig. 6, presents the range and the average calculated values of current efficiency for the

357 electrochemical cell using different cathode materials and at different operating temperatures. The 358 current efficiency of hydrogen gas production decreases with an increase in the operating 359 temperature of the eutectic molten hydroxide. For example, as temperature increases from 225 to $360300{ }^{\circ} \mathrm{C}$, the current efficiency decreases from $101.6 \%$ to $68.0 \%$ using nickel metal as the cathode 361 and graphite as the anode. The reason for being the current efficiency about $101.6 \%$ at $225^{\circ} \mathrm{C}$ 362 using nickel cathode can be explained as an experimental error. For use stainless steel and platinum 363 cathodes, the current efficiencies were $115.3 \%$ and $102.3 \%$ respectively at $225^{\circ} \mathrm{C}$. The reason for 364 being the current efficiency of them more than $100 \%$ is explained as an experimental error 365 happened at this specific operating temperature. The reason for the decrease in current efficiency 366 for hydrogen generation with an increased temperature of the eutectic molten hydroxide is because 367 the formation of superoxide $\mathrm{O}^{2-}$ reduction increases and subsequently competes with the hydrogen 368 formation reaction [11] as seen in Eqs. (4) and (5): 
373 This finding relating to the decrease in current efficiency with increasing temperature and applied

374 voltage respectively; and is not in agreement with the current efficiency findings for hydrogen gas

375 production using stainless steel as an anode. The only exception to this rule was using platinum as

376 the cathode. In conclusion, the current efficiency increases with an increase

377 in the operating temperature of the eutectic molten hydroxide (for all cathode materials) and

378 increasing the applied voltages in case of using either nickel or stainless steel as the cathode during

379 electrolysis.

\section{4. Conclusions}

This study finds that steam splitting assisted the eutectic molten hydroxide electrolysis at

382 high operating temperatures for hydrogen gas production, and is the way forward to reduce applied 383 voltages. For the nickel cathode, the increase in the current directly affected the hydrogen gas flow 384 rate at the cathode. Comparatively $\mathrm{Ni}$ cathode against stainless steel anode proved a good 385 combination. The achieved current efficiency for $\mathrm{Ni}$, increased from $63.2 \%$ to $90.5 \%$ with an 386 increase in the operating temperature from 225 to $300{ }^{\circ} \mathrm{C}$ respectively. For the platinum cathode, 387 the flow rate of hydrogen gas production increased from 1.6 to $4.5 \mathrm{~cm}^{3} \mathrm{~min}^{-1}$ with an increase in 388 the applied voltage from 1.5 to $2.5 \mathrm{~V}$ at $300{ }^{\circ} \mathrm{C}$. For the stainless steel cathode and anode, the 389 hydrogen gas flow rate also increased from 2 to $7 \mathrm{~cm}^{3} \mathrm{~min}^{-1}$. However, when the graphite anode 390 was used during electrolysis, the response of the current increased with an increase in the operating 391 temperature. The subsequent production rate also increased, but the current efficiency decreased 392 with an increase in the operating temperature for all three cathode materials. This behaviour can 393 be attributed to the carbon particles that obstruct the reduction process by blocking the pore of the 
394 oxide and preventing the oxide from coming in contact with the electrolyte. Cost effective

395 electrode material, with good stability and catalytic nature electrolyte will be a good option for the

396 anodic electrode under these conditions for $\mathrm{H}_{2}$ gas production. 


\section{References}

398 1. Yüksel, H., et al., Int. J. Hydrogen Energy. 43 (23) (2018) 10586-10594.

399 2. Dincer, I. and C. Acar, Int. J. Hydrogen Energy. 40(34) (2015) 11094-11111.

400 3. Acar, C. and I. Dincer, J. Clean. Prod. 218 (2019) 835-849.

4014 4. Kothari, R., D. Buddhi, and R. Sawhney, Renew. Sust. Energ. Rev. 12(2) (2008) 553-563.

402 5. Cuce, E., et al., Intl J Ambient Energy. 40(1) (2019) 86-95.

403 6. Mansilla, C., et al., Energy. 32(4) (2007) 423-430.

404 7. Al-Shara, N.K., et al., Int. J. Hydrogen Energy. 44 (50) (2019) 27224-27236.

405 8. Kato, T., et al., Energy. 30 (14) (2005) 2580-2595.

406 9. Ipsakis, D., et al., Renew. Energy. 125 (2018) 806-818.

407 10. Balat, M., Int. J. Hydrogen Energy. 33(15) (2008) 4013-4029.

408 11. Licht, S., et al., J. Electrochem. Soc. 163(10) (2016). 1162-1168.

409 12. Al-Shara, N.K., et al., J. Energy Chem. 49 (2020) 33-41.

410 13. Nagai, N., et al., Int. J. Hydrogen Energy. 28 (1) (2003) 35-41.

411 14. Licht, S., et al., Science. 345(6197) (2014) 637-640.

412 15. Ganley, J.C., Int. J. Hydrogen Energy. 34(9) (2009) 3604-3611.

413 16. Anani, A., et al., J. Electrochem. Soc. 137(9) (1990) 2703-2709.

414 17. Selembo, P.A., et al., J. Power Sources. 190(2) (2009) 271-278.

415 18. Chaurasia, A.K., et al., Int. J. Hydrogen Energy. (2019).

416 19. Hino, R., et al., Nucl. Eng. Des. 233(1-3) (2004) 363-375.

417 20. Kim, K.H., et al., J. Environ. Manage. 232 (2019) 330-335.

418 21. Du, X., et al., Chem. Sus. Chem. 10(5) (2017) 847-854.

419 22. Bozzini, B., et al., Mater. Corros. 63(11) (2012) 967-978.

420 23. Bicer, Y. and I. Dincer, ACS Sustain. Chem. Eng. 5(9) (2017) 8035-8043.

421 24. Guo, K., et al., J. Power Sources. 356 (2017) 484-490.

422 25. Chen, R., et al., ACS Energy Lett. 2(5) (2017) 1070-1075.

423 26. Zhou, M., et al., ACS Nano. 12(5) (2018) 4148-4155.

424 27. Cai, W., et al., Biosens. Bioelectron. 80 (2016) 118-122.

425 28. Doenitz, W., et al., Int. J. Hydrogen Energy. 5(1) (1980) 55-63.

426 29. De Souza, R.F., et al., J. Power Sources. 164(2) (2007) 792-798.

427 30. Vidales, A.G., et al., Int. J. Hydrogen Energy. 43(29) (2018) 12917-12928.

428 31. Cox, A. and D.J. Fray, J. Appl. Electrochem.38(10) (2008) 1401-1407. 


\section{List of Tables}

431

Table 1. Dimensions of the electrodes.

\begin{tabular}{lccc}
\hline Electrode material & Diameter $(\mathrm{cm})$ & Depth $(\mathrm{cm})$ & Surface area $\left(\mathrm{cm}^{2}\right)$ \\
\hline Nickel & 0.5 & 1.5 & 2.55 \\
Platinum wire & 0.05 & $1.5 \times 10.8$ & 2.55 \\
Stainless steel & 0.5 & 1.5 & 2.55 \\
Graphite & 1.0 & 1.5 & 5.50 \\
\hline
\end{tabular}

\section{List of Figures}

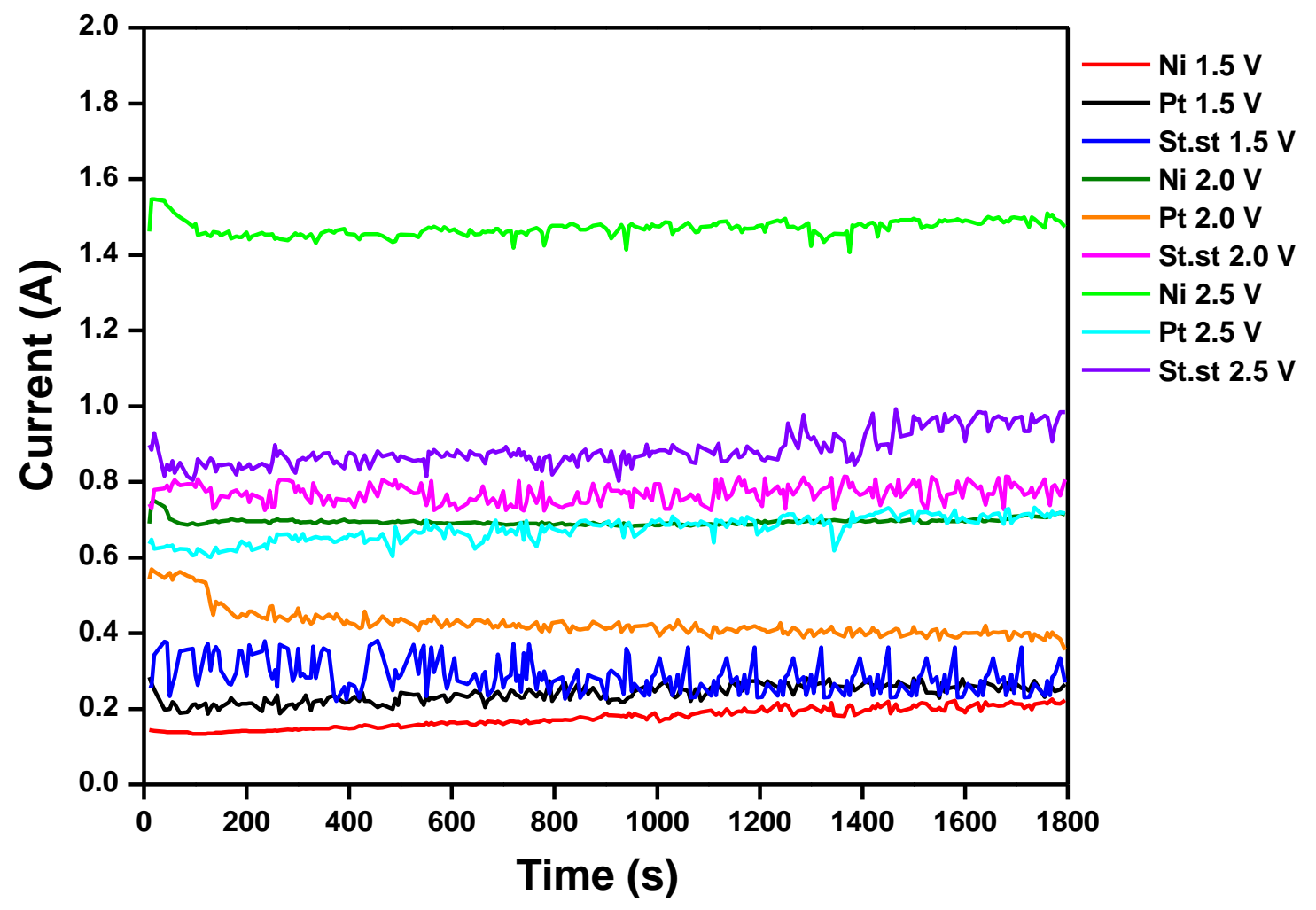

435 Fig. 1. Current-time plots @ stainless steel anode, vs Ni, Pt, and St.st cathodes recorded for 1800 $436 \mathrm{~s}$ electrolysis at a temperature of $300^{\circ} \mathrm{C}$ and applied voltages of $1.5 \mathrm{~V}, 2.0 \mathrm{~V}$ and $2.5 \mathrm{~V}$. 

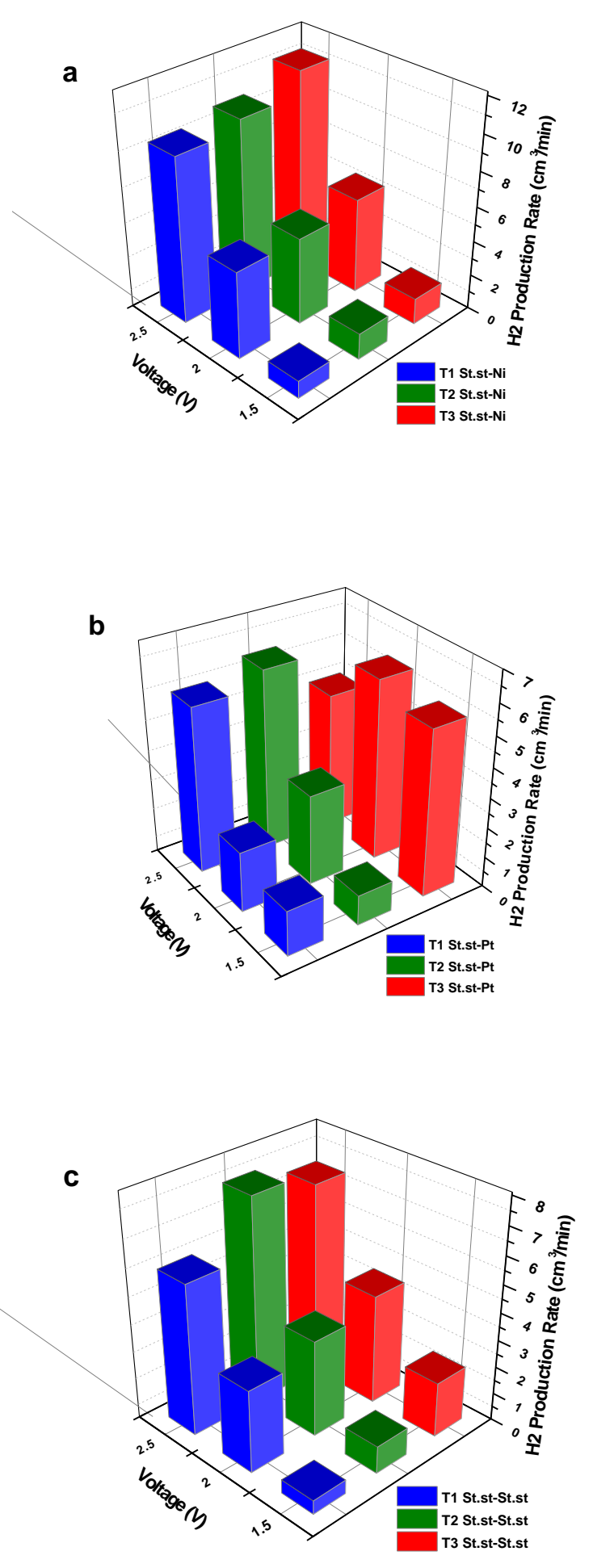

440 Fig. 2. Hydrogen gas production rate versus applied voltages at various operating temperatures; $441 T 1\left(225^{\circ} \mathrm{C}\right), T 2\left(250{ }^{\circ} \mathrm{C}\right)$ and $T 3\left(300^{\circ} \mathrm{C}\right)$ with St.st anode and different cathode materials; (a) $\mathrm{Ni}$, 442 (b) Pt and (c) St.st. 


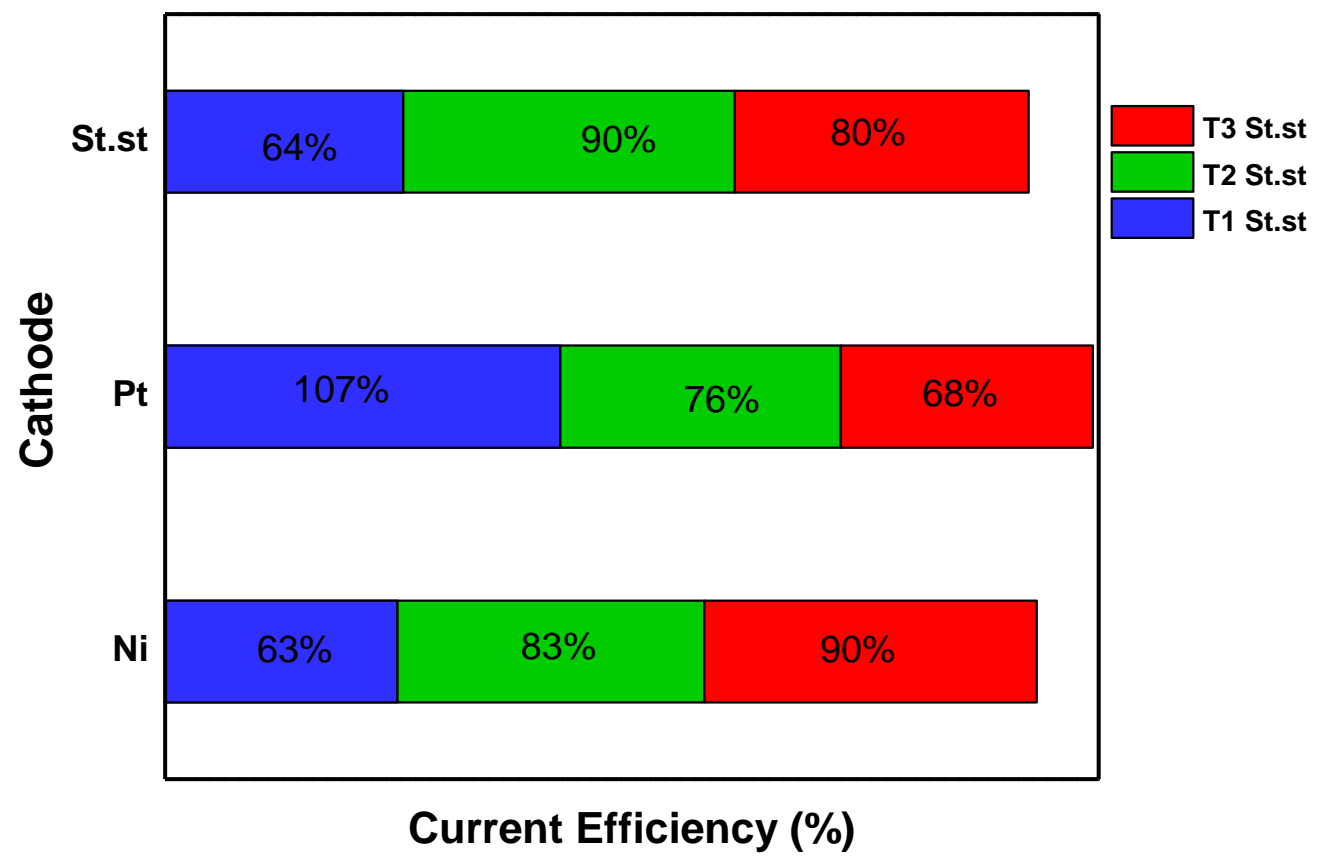

444

445

446

Fig. 3. Current efficiency of electrochemical cell for hydrogen gas production at different 447 operating temperatures; $T 1\left(225^{\circ} \mathrm{C}\right), T 2\left(250{ }^{\circ} \mathrm{C}\right)$ and $T 3\left(300^{\circ} \mathrm{C}\right)$ with St.st anode.

448 


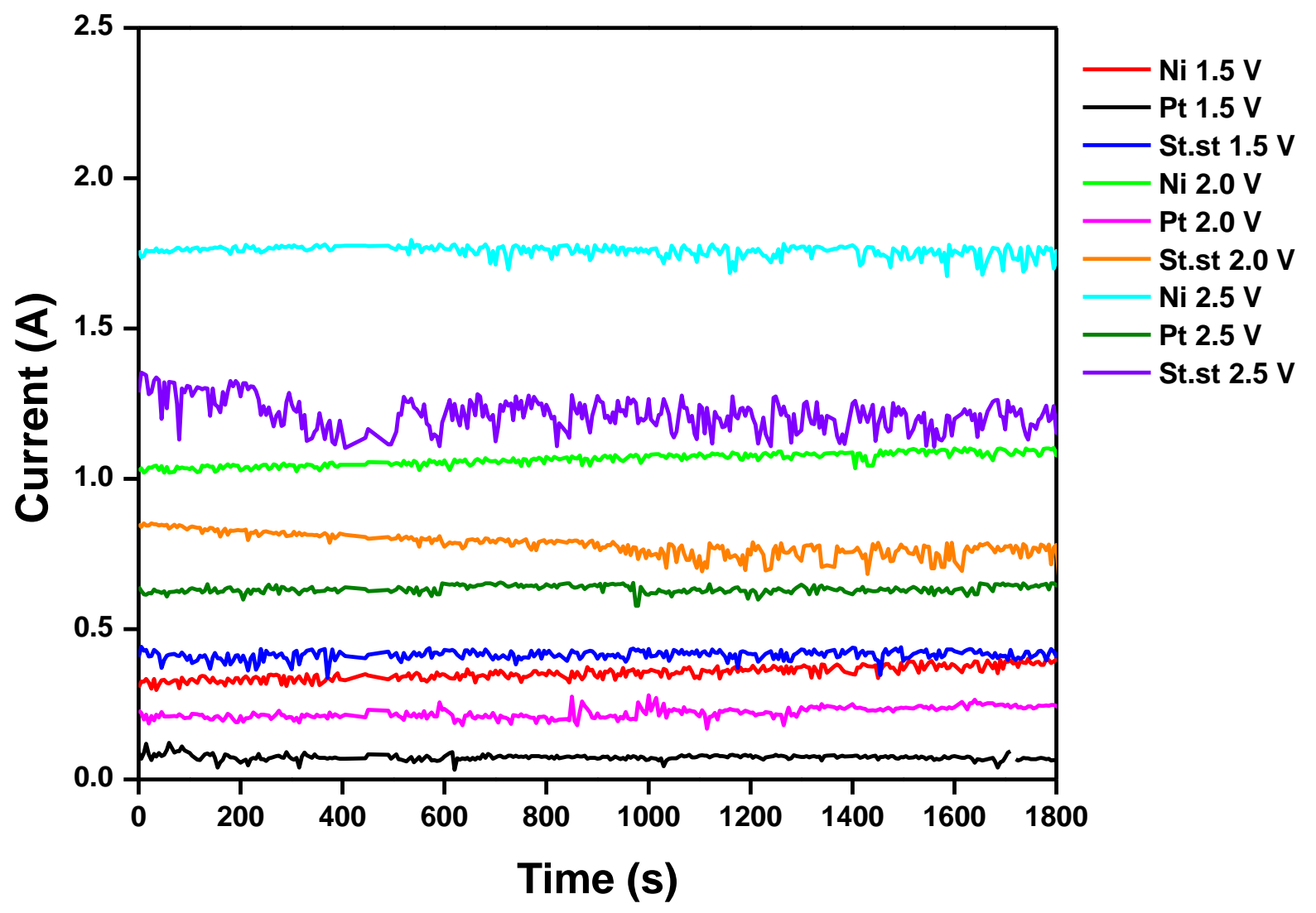

450 Fig. 4. Current-time plots @ graphite anode vs. Ni, Pt and St.st cathodes recorded for $1800 \mathrm{~s}$ 451 electrolysis at $300{ }^{\circ} \mathrm{C}$ temperature with different applied voltages; $1.5 \mathrm{~V}, 2.0 \mathrm{~V}$ and $2.5 \mathrm{~V}$. 


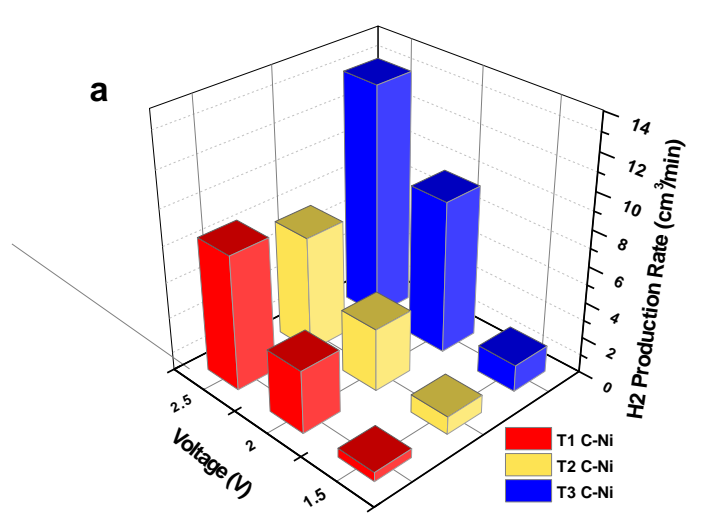

453

454

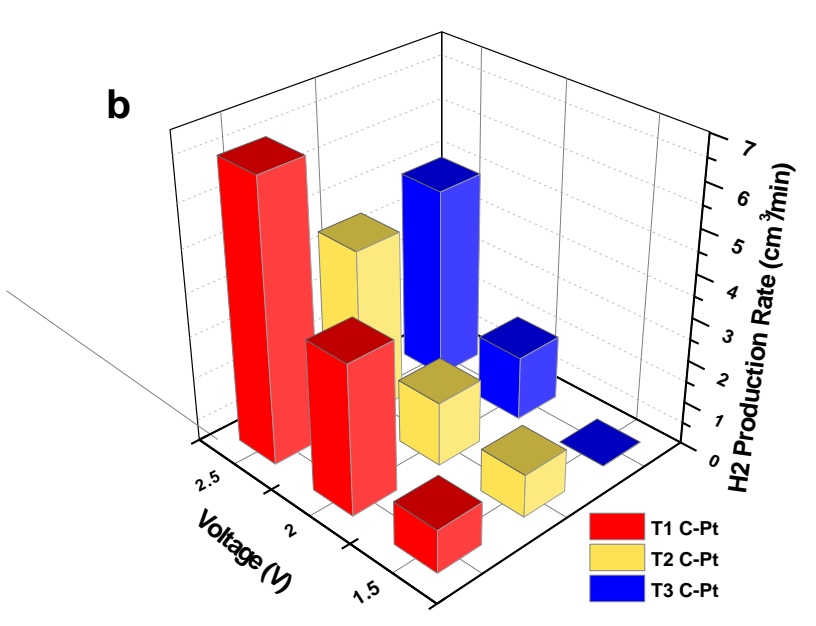

455

456

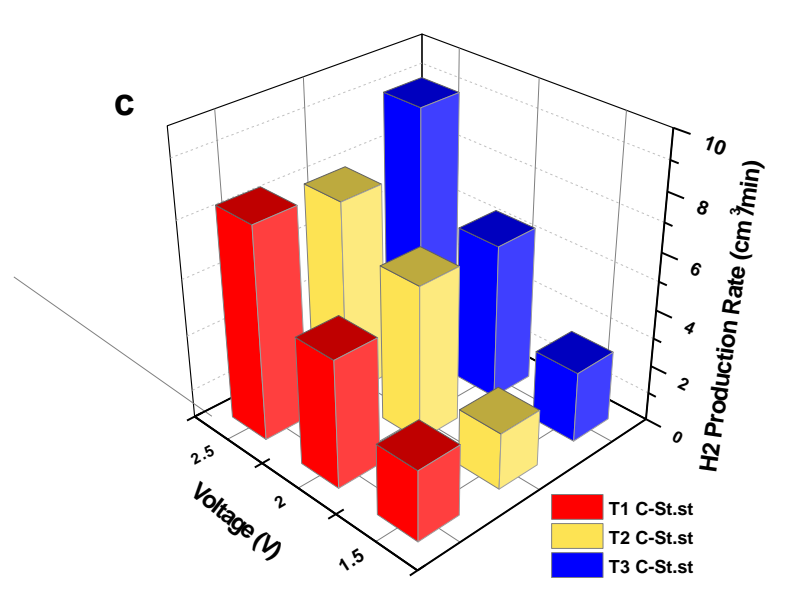

458 Fig. 5. Hydrogen gas production rate versus applied voltages at different operating temperatures; $459 T 1\left(225^{\circ} \mathrm{C}\right), T 2\left(250^{\circ} \mathrm{C}\right)$ and $T 3\left(300^{\circ} \mathrm{C}\right)$ with graphite anode and various cathode materials; (a) $460 \mathrm{Ni}$, (b) Pt and (c) St.st. 


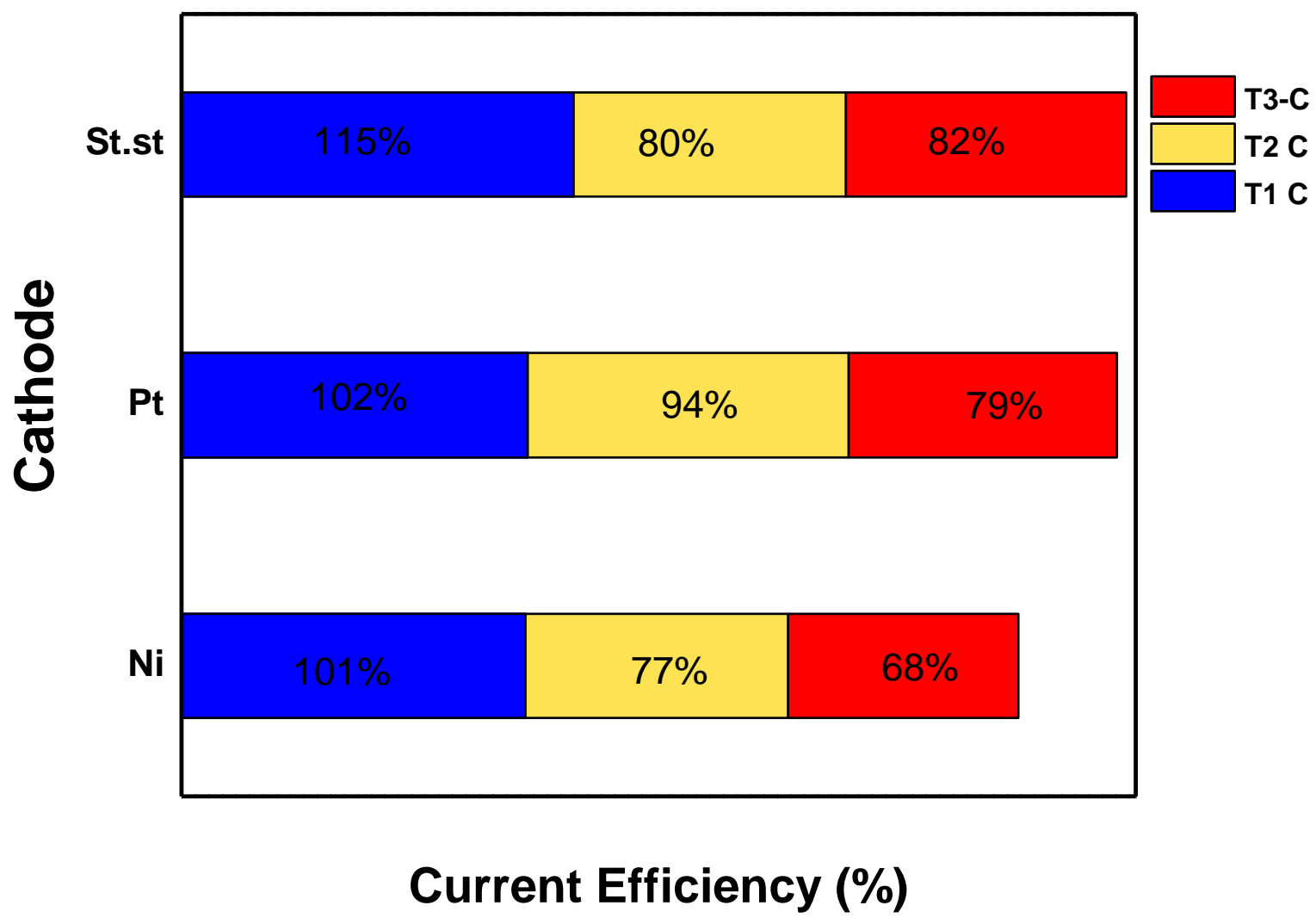




\section{Graphical abstract}

470 Various combinations of cathode, anode, temperature and voltage have been tested for

471 optimization of best working conditions with molten hydroxide for $\mathrm{H}_{2}$ gas production. Steam

472 splitting is an encouraging alternate methodology for $\mathrm{H}_{2}$ fuel production.

473

474

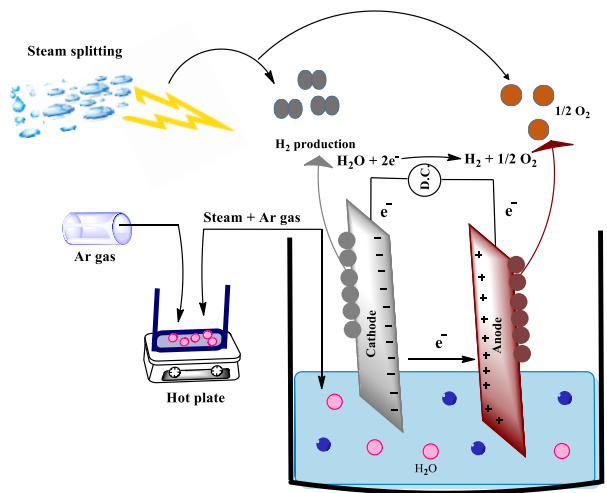

475 